\title{
Estrategias del Estado mexicano para minimizar los feminicidios
}

\author{
Javier Juárez Rodríguez' (iD) 0000-0001-9441-8229 \\ Nora Elena Botero Escobar ${ }^{1}$ \\ 0000-0002-9064-834X \\ Natalia Grisales Ramírez' (iD) 0000-0003-4978-331X \\ 'Universidad de Medellín, Facultad de Comunicación, Medellín, Colombia. \\ corresrec@udem.edu.co
}

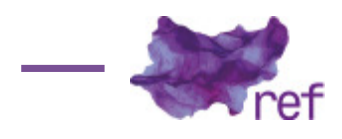

Resumen: Este artículo es producto de una investigación empírica realizada en Ciudad Juárez (México), que analizó los efectos que el proceso de militarización que allí se realizó entre 2008-2015 tuvo en las desapariciones y feminicidios de mujeres. El trabajo, que aporta datos y análisis actualizados sobre este fenómeno, tiene como objetivo evidenciar la existencia de estrategias de las autoridades para minimizar los hechos y culpabilizar a las víctimas. Para el desarrollo de esta investigación, se recurrió a trabajos y autoras referentes en el marco de los estudios de género, así como de los feminicidios en Juárez, soportado todo ello en una labor documental reforzada con datos oficiales de la Fiscalía e informes de organizaciones no gubernamentales. Se empleó una metodología de enfoque cualitativo donde primó la etnografía, con el empleo de la observación participante y la realización de entrevistas personales.

Palabras Clave: Feminicidios, Estado, Militarización, Patriarcado, México.

\section{As estratégias do governo mexicano para diminuir os feminicídios}

Resumo: O artigo é resultado da pesquisa empírica realizada em Ciudad Juárez (México), onde foram analisados os efeitos do processo de militarização entre 2018 e 2015, em relação com as desaparições e os assassinatos de mulheres. O trabalho aporta dados e uma análise atualizada do fenômeno, assim como evidencia a existência de estratégias das autoridades para minimizar os fatos e responsabilizar as vítimas. Para o estudo foram utilizados trabalhos e autoras destacadas na área dos estudos de gênero e dos feminicídios em Juárez, dados oficiais da Fiscalía, e informes de organismos não governamentais. A metodologia empregada foi de caráter qualitativo, privilegiando a etnografia, a observação participante e a realização de entrevistas.

Palavras chave: Feminicídio, governo, militarização, patriarcado, México.

\section{Strategies of the Mexican State to Underestimate Femicides}

Abstract: This article analyses the connections between the militarization processes in Ciudad Juárez (Mexico), from 2008 to 2015, and women's disappearances and femicides. This work provides updated data and analysis on this phenomenon, and aims to demonstrate the existence of strategies by the authorities to underestimate the facts and blame them on the victims. Our analysis relies on seminal works on gender studies, and is supported by documentary work with official data from Ciudad Juarez's Prosecutor Office, as well as on reports from non-governmental organizations. We used a methodology of qualitative approach where ethnography prevailed, conducting participant observation, as well as personal interviews.

Keywords: Femicides, State, Militarization, Patriarchy, Mexico. 


\section{Introducción}

Ciudad Juárez es el municipio más poblado del Estado de Chihuahua (México)' y se encuentra ubicado en la frontera norte del país, frente a El Paso, Texas. Para analizar el contexto sociocultural de la ciudad y su entorno desde una perspectiva histórica, debemos tener presente dos elementos claves que han marcado su devenir:

1. Su condición de urbe en disputa cuasi permanente por parte del crimen organizado como consecuencia de su situación geográfica estratégica.

2. Su consolidación como una ciudad para el trabajo por la proliferación de la industria maquiladora y su consecuente reafirmación como urbe que atrae a un gran número de población migrante, unida históricamente a una preocupante desatención del Estado, que ha derivado en un desarraigo social creciente.

Gran parte de las mujeres victimadas, sobre todo entre 1993 y 2006 , eran trabajadoras de la maquila, secuestradas antes de entrar a sus trabajos o cuando se disponían a buscar transporte público para regresar a sus hogares tras su jornada laboral. A partir de 1993, en el contexto de una etapa marcada por el auge económico e industrial de la ciudad y su entorno, comenzarán a denunciarse públicamente y a documentarse numerosos casos de feminicidios sexuales. Sin embargo, algunos investigadores, como Alfredo Limas (Universidad Autónoma de Ciudad Juárez), destacan en este sentido que "el hecho de que comenzara a visibilizarse la comisión de estos feminicidios sexuales a partir de entonces no significa que no existieran antes de esta fecha" (Entrevista personal realizada en diciembre de 2014), una afirmación compartida por periodistas e investigadoras reconocidas por su amplio conocimiento y seguimiento de esta problemática, entre ellas Julia Estela Monárrez (Investigadora del Colegio de la Frontera Norte) o Rosa Isela Pérez (Redactora de Norte de Ciudad Juárez).

Años antes, activistas e investigadoras, como Diana Russell o Jane Caputi (Margareth BULLEN; Carmen DÍEZ, 2008), comenzaron a acuñar el término feminicide para visibilizar estos asesinatos fundamentados en razones de género, es decir, asesinatos de mujeres por el hecho de ser mujeres. Esta expresión será también defendida por la investigadora mexicana Marcela Lagarde (2008) quien bajo el término feminicidio conceptualizará estos crímenes de odio permitidos y avalados por unos condicionantes sociales y culturales fundamentados en una "desigualdad estructural entre mujeres y hombres" (2008, p.216-217). Lagarde engloba este fenómeno en el marco de lo que denomina como una violencia feminicida que permite la "violación de los derechos humanos de las mujeres, tanto en Ciudad Juárez como en el país" (LAGARDE, 2008, p. 218), y que implica "una forma extrema de violencia de género contra las mujeres" conformada por un "conjunto de conductas misóginas que pueden conllevar impunidad social y del Estado y culminar en homicidio y otras formas de muerte violenta de mujeres". ${ }^{2}$

El esfuerzo de activistas e investigadoras visibilizó la existencia de decenas de casos de mujeres y adolescentes desaparecidas en Ciudad Juárez, cuyos cuerpos fueron localizados posteriormente con signos de tortura y, en la mayoría de los casos, violaciones tumultuarias (MONÁRREZ, 2010). Este fue el inicio de la documentación de un feminicidio sexual sistemático, marcado por una preocupante impunidad y una latente indolencia gubernamental, el cual fue analizado a profundidad desde una óptica científica por investigadoras de un contrastado prestigio internacional, como Marcela Lagarde, Rita Laura Segato o Julia Estela Monárrez, entre otras. Paralelamente, la labor de periodistas como Sergio González (2002) (autor de Huesos en el desierto y redactor de la Revista Proceso), Rosa Isela Pérez (redactora del diario Norte de Ciudad Juárez) o Diana Washington (2005) (autora del libro Cosecha de Mujeres: Safari en el desierto mexicano y periodista de EI Paso Times), fue fundamental para documentar las similitudes existentes entre muchas de las víctimas, las cuales obedecían a un claro perfil: jóvenes de entre 16 y 20 años, secuestradas en la zona centro o cuando se disponían a entrar o salir de la maquila, muchas veces a plena luz del día, y cuyos cuerpos eran localizados después con notables signos de tortura y agresiones sexuales. La redactora de El Paso Times recuerda que al investigar estos capítulos fue:

Consciente de lo que hay detrás, quiénes están detrás (...) al inicio nunca imaginé que el problema era tan grande, con personas poderosas involucradas, asesinos en serie que siguen libres (...) siguen los feminicidios (...) en Juárez hay dos ejércitos de narcotráfico, dos cárteles, sicarios, policía corrupta, es casi imposible investigar (...) las autoridades saben y sabían quiénes estaban cometiendo estos crímenes. No pudieron hacer nada, porque sus superiores cerraron las investigaciones. (Javier JUÁREZ, 2015, p.157-158)

\footnotetext{
' Según el INEGI - Instituto Nacional de Estadística (2015) el Estado de Chihuahua, en el que se ubica Juárez, representa el $12 \%$ del total de la República. Según datos de 2015, Ciudad Juárez contaba con 1.39180 habitantes, por encima de la propia capital del Estado.

${ }^{2}$ Artículo 21 de la Ley General de Acceso de las Mujeres a una Vida Libre de Violencia aprobada en 2007 y promovida por Marcela Lagarde.
} 
Como señala Washington, los feminicidios y desapariciones forzosas de niñas y mujeres de Ciudad Juárez siguen siendo un ejemplo paradigmático de impunidad, sustentado en un sistema que potencia la misoginia y la violencia sexual contra las mujeres, "y que su expresión máxima es el asesinato de la mujer, con el cual se produce una estrategia de mantenimiento del control patriarcal (...) la violencia contra las mujeres es producto de pactos patriarcales" (Patricia RAVELO, 2008, p. 1-2). Como señala Patricia Ravelo, no se puede desligar la historia reciente de la ciudad fronteriza de una cultura de la violencia y pactos patriarcales potenciados por la corrupción, la consolidación de las estructuras del crimen organizado y la disputa de los brazos armados de los cárteles del narcotráfico por el control de la zona. No sólo Ciudad Juárez, sino todo su entorno, se han consolidado como zonas atractivas para polleros, ${ }^{3}$ así como halcones ${ }^{4}$ y narcotraficantes, lo que ha desembocado en guerras cruentas entre los brazos armados de estas estructuras.

Tras un período de relativa calma motivada por el control de la zona por parte del Cártel de Ciudad Juárez, Los Artistas Asesinos (Cártel de Sinaloa) y Los Aztecas (Cártel de Juárez) emprendieron, a partir del año 2007, una guerra sin cuartel para lograr el control de la codiciada plaza juarense, dejando más de 7.000 homicidios entre 2007 y 2012 (ambos años incluidos). A partir de entonces se iniciará una escalada de violencia, que será respondida por el Gobierno de Felipe Calderón (PAN), a partir de 2008, con una estrategia de militarización a través del Operativo Conjunto Chihuahua; sin embargo, la llegada de miles de integrantes de las Fuerzas de Seguridad no supuso un descenso de la inseguridad y/o los crímenes en la ciudad fronteriza, sino todo lo contrario. David Brooks (2013) destaca en este sentido que sólo en ocho años (2006-2013) se presentaron más de 26.000 quejas y denuncias contra miembros de las fuerzas de la seguridad por "tortura, violación sexual, asesinato extrajudicial, desaparición y detención arbitraria, entre otros". Las violaciones a los derechos humanos aumentaron notablemente a raíz del proceso de militarización, siendo un número importante de las víctimas, directas y/o indirectas, mujeres. Según la Convención sobre la Eliminación de todas las Formas de Discriminación contra la Mujer (CEDAW): "Entre 2007 y 2011 , se registraron 92 denuncias ante la Comisión Estatal de Derechos Humanos en Chihuahua, 36 desapariciones forzadas, en varias de ellas se ha señalado al ejército mexicano y a la policía federal como responsables" documentándose entre 2009 y 2010 "1.017 denuncias por abusos de militares y policías - integrantes del Operativo Conjunto" (CEDEHM, 2012, p.16-17).

Si bien es cierto que Ciudad Juárez acaparó numerosas portadas en medios internacionales, y que fue objeto de estudio y análisis desde una perspectiva científica, poco a poco el foco mediático y académico fue desplazándose lejos de la ciudad fronteriza. Esta ausencia de seguimiento investigativo y la falta de una labor etnográfica en muchos de los estudios posteriores propiciaron la comisión de graves errores y la repetición de datos, afirmaciones y lecturas obsoletas, carentes de rigor. Por ello, esta investigación cobra más relevancia aún en el empeño de aportar una revisión analítica rigurosa y actualizada sobre los capítulos de violencia estructural contra niñas y mujeres en Ciudad Juárez a partir del año 2007, fijando más concretamente su estudio en el período comprendido entre 2008 y 2013.

A lo largo de los seis años analizados, más de 800 mujeres fueron asesinadas en Juárez, datos muy superiores a los registrados entre 1993 y 2007; más de un centenar de mujeres/niñas fueron reportadas como desaparecidas. Atendiendo a los datos oficiales aportados por la Fiscalía Especializada en Atención a Mujeres Víctimas del Delito por Razones de Género en Ciudad Juárez, entre el 1 enero de 2008 y el 31 diciembre de 2012, un total de 117 mujeres fueron reportadas desaparecidas en Ciudad Juárez, en su mayoría adolescentes cuyas edades oscilaban en la mayor parte de los casos entre los 13 y los 18 años. Respecto a los patrones detectados en los casos, es significativo que una gran parte de ellas fueron vistas por última vez en el centro de la ciudad, buscando trabajo, realizando compras o saliendo de la escuela para regresar a sus casas.

La localización, entre 2011 y 2013, en municipios muy alejados de Juárez, situados en la carretera Praxedis-Porvenir (Valle de Juárez) de restos óseos correspondientes a al menos medio centenar de mujeres reportadas desaparecidas meses e incluso años antes (entre 2008 y 2011), evidencia la magnitud y la gravedad de los hechos que rodean a los capítulos de desapariciones de niñas y mujeres. Más de medio centenar de ellas siguen aún hoy en calidad de desaparecidas. Nos situamos ante un feminicidio sistemático en el que se une una doble condición transversal en las victimadas: son mujeres y pobres. Nos situamos ante crímenes de odio en los que, como señala el investigador Alfredo Limas, se solapa el doble componente género-clase, centrándose en "mujeres de cierto sector social, vulnerable, usadas por el barón feudal para ejercer sobre ellas todo tipo de violencia, con víctimas sacrificiales" (Alfredo LIMAS, 2014, p.82).

\footnotetext{
${ }^{3}$ Término acuñado en México para referirse a aquellos que trafican ilegalmente con personas.

${ }^{4}$ Persona pagada por el crimen organizado para vigilar espacios estratégicos y avisar ante la llegada de desconocidos o miembros de las estructuras delincuenciales rivales.
} 


\section{Desarrollo de la investigación}

Como hemos adelantado, los capítulos de feminicidios y desapariciones sistemáticas de mujeres y niñas en Ciudad Juárez no son un fenómeno novedoso y ni mucho menos se inicia a darse a partir del año 2008. Ya en 1993 comenzaron a documentarse numerosos casos de desapariciones de mujeres jóvenes, gran parte de ellas trabajadoras de la industria maquiladora, cuyos cuerpos eran localizados posteriormente con evidentes signos de tortura y violencia sexual. Como señala la investigadora Mariana Berlanga (2015), "el feminicidio con el patrón de Juárez inauguró una dimensión expresiva de la violencia contra las mujeres” (p. 106), escribiéndose, a través de la violencia narrada sobre el cuerpo femenino, mensajes de odio y poder (Rita Laura SEGATO, 2013) mediante crímenes en los que convergían numerosos factores comunes, que fueron objeto de análisis tanto desde el punto de vista científico como desde el periodístico.

La impunidad rodeó y provocó su perpetuación y su normalización a lo largo de los años, con unas autoridades más preocupadas por desacreditar a las propias víctimas y sus familias que por abordar de forma real y efectiva las investigaciones de estos crímenes (JUÁREZ, 2015, p.270). Si bien es cierto que la gran mayoría de estudios de este fenómeno arrancan en 1993, como hemos adelantado, hay investigadoras como Julia Estela Monárrez (2004) que fechan el inicio de estos capítulos años atrás. En su estudio "Elementos de análisis del feminicidio sexual sistémico en Ciudad Juárez para su viabilidad jurídica", Monárrez (2004), una de las voces más legitimadas y prestigiosas a la hora de analizar este fenómeno, demuestra que los feminicidios sexuales en Ciudad Juárez comenzaron antes de 1993, aportando, además, notas periodísticas que avalan su planteamiento.

Ciudad Juárez se convertirá a lo largo de los años en un ejemplo paradigmático de consolidación de estos crímenes, así como de una latente permisividad gubernamental. Como señala la propia Julia Monárrez, esta discriminación por razones de género "es histórica" y debe ser analizada en un contexto más amplio de "subordinación de la mujer en todo México" (JUÁREZ, 2015, p.62). Los feminicidios documentados en Ciudad Juárez deben ser analizados en el marco de una sociedad, la mexicana, estructuralmente patriarcal y hostil hacia la mujer, que se agudiza en Ciudad Juárez por los numerosos factores que se concretan en ella, como su condición estratégica de ciudad fronteriza, su consolidación como espacio en disputa por parte de estructuras del crimen organizado o la desigualdad social existente, agudizada por unos elevados índices de pobreza (según datos de la Comisión Nacional de Evaluación de la Política de Desarrollo Social - CONEVAL - del año 2010 , el $40 \%$ de la población total de Juárez vive en condiciones de pobreza), y una creciente feminización de la misma (Alda FACCIO, 1999). Ni la llegada y el auge de la industria maquiladora, ni los exitosos datos macroeconómicos de la ciudad durante años consiguieron fortalecer una clase media sólida capaz de mitigar el clima de inseguridad y hostilidad hacia las mujeres, mayoritarias, a su vez, en la mano de obra trabajadora de la maquila a lo largo de estos años.

Las autoridades culpabilizarán a activistas, periodistas y las propias familias de mujeres asesinadas o desaparecidas (MONÁRREZ 2009, p. 52-53), desplegando una estrategia argumental, social y política para que estos crímenes de odio sigan presentes a lo largo del tiempo y para que, a pesar de los cambios de las sucesivas administraciones, la situación real no evolucione cualitativamente. Como demuestra Monárrez (2009, p.39) la "alternancia política (...) ha demostrado a través de sus líderes, con algunas variantes, el mismo discurso, sexista, clasista, antidemocrático y hegemónico contra quienes exigen justicia".

El esfuerzo llevado a cabo por las propias familias, organizándose de forma conjunta con movimientos exitosos como, por ejemplo, Voces Sin Eco, Justicia para Nuestras Hijas, Nuestras Hijas de Regreso a Casa o más recientemente el Comité de Madres de Mujeres Desaparecidas, así como la labor de denuncia de periodistas como Rosa Isela Pérez, Diana Washington o Sergio González, y/ o las valiosas aportaciones de investigadoras como Julia Estela Monárrez, Patricia Ravelo o Marcela Lagarde, entre otras, consiguieron avanzar notablemente en la visibilización y el análisis del trasfondo que subyace tras un fenómeno que, como analizamos a continuación, se agudizará a partir del año 2007, coincidiendo con el sexenio de Felipe Calderón, quien "declarara la llamada Guerra contra el narcotráfico" (Mariana BERLANGA, 2015, p.106), escenificada con un proceso progresivo de militarización de la ciudad y su entorno, lo que supuso un estallido de violencia acompañado por un aumento de los feminicidios y las desapariciones de mujeres. Las autoridades, lejos de afrontar esta realidad y declarar la Alerta de Género, ${ }^{5}$ optaron, primero, por restar importancia a los hechos y, en segundo lugar, evadir sus responsabilidades tratando de culpabilizar, sin pruebas ni investigaciones sólidas, a las propias víctimas, englobando estos capítulos dentro del contexto general de narcoviolencia y conectando a las víctimas, de forma directa o indirecta, con el crimen organizado, justificando de este modo los feminicidios y secuestros de las jóvenes.

\footnotetext{
${ }^{5}$ Conjunto de acciones gubernamentales de emergencia para enfrentar y erradicar la violencia feminicida en un
} territorio determinado. 
Según el Colegio de la Frontera Norte de Ciudad Juárez, entre 2008 y 2013 (seis años) fueron asesinadas en Ciudad Juárez casi el doble de mujeres (940) que en el período comprendido entre 1993 y 2007 (15 años), donde fueron documentos 501 casos de feminicidio, un dato ilustrativo, teniendo en cuenta que mientras que en la década de los 90 estos capítulos tuvieron una gran repercusión y seguimiento internacional, los registrados entre 2008 y 2013 han obtenido mucha menos relevancia en medios y estudios científico. El contexto de violencia generalizado durante estos años fue el marco perfecto para invisibilizar el aumento desmesurado de la violencia feminicida contra mujeres y niñas documentado en Ciudad Juárez. La explosión bélica desatada entre cárteles y la militarización de la zona, hizo que la urbe fuera catalogada en 2012 como la "ciudad más peligrosa del mundo", ${ }^{\circ}$ y difuminó por completo la violencia feminicida, lo que favoreció, además, a las estrategias gubernamentales para minimizar, e incluso, invisibilizar estos hechos, culpando a las propias víctimas sin prueba ni investigación alguna, como analizamos a continuación.

\section{Gráfica 1}

\section{FEMINICIDIOS CIUDAD JUÁREZ}

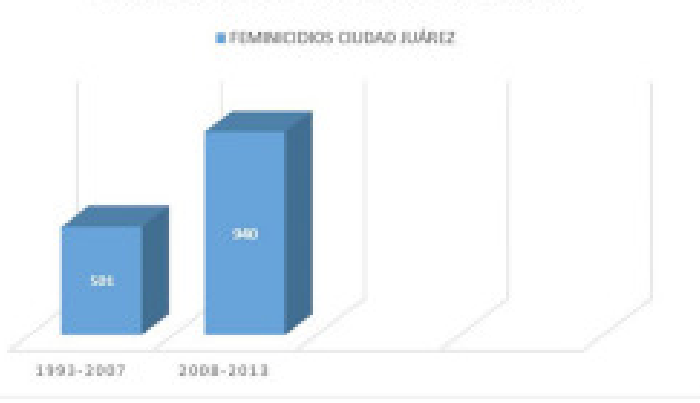

\begin{abstract}
\#PraTodoMundoVer Gráfica comparativa en barras azules presenta la evo-lución de los feminicidios en Ciudad Juárez entre los años 19932007 (501) y 2008-2013 (940). Elaboración propia a partir de los datos obtenidos del Colegio de la Frontera Norte.
\end{abstract}

La violencia contra las mujeres en Ciudad Juárez a partir del año 2008 alcanzó unos picos sin precedentes, que vendrán acompañados por una creciente impunidad, la cual será la mejor garantía de protección para estas redes feminicidas difuminadas en el clima de violencia creciente en la urbe y su entorno. El aumento de las denuncias por desapariciones de mujeres y adolescentes vino unido a un incremento de los feminicidios en Ciudad Juárez que, como se refleja en el informe "Juárez y Chihuahua: Guerra contra el narcotráfico y recomendaciones de la CEDAW": "Ha tenido el mayor número de mujeres asesinadas en todo el país. De acuerdo con cifras oficiales, en los últimos años, se registró un aumento de más de 1.000\% de asesinatos de mujeres" (CEDEHM, 2012, p. 3). Justicia Para Nuestras Hijas (JPNH) cifra en el citado informe en 105 el número de desaparecidas entre 2008 y 201 1; según JPNH, de las más de 100 jóvenes reportadas desaparecidas entre 2008 y 2011 en Ciudad Juárez, el 60\% eran menores de edad y guardaban rasgos físicos similares.

Podemos afirmar que nos situamos ante una nueva generación de mujeres víctimas de feminicidio, con características similares, pero también diferencias respecto a las jóvenes víctimas de feminicidio y/o desaparición documentadas entre 1993 y 2006 . En este sentido, la mayor parte de las mujeres víctimas entre 2008 y 2013 eran estudiantes o trabajadoras de pequeños comercios de la zona centro; es decir, los perfiles han ido mutando entre la década de los 90 y el año 2008, ya que ahora no nos situamos ante casos de mujeres trabajadoras de la industria maquiladora que son abordadas cuando se disponen a entrar al trabajo o al terminar su jornada laboral (JUÁREZ, 2015). Hablamos, de un nuevo perfil en el que, mayoritariamente, son víctimas adolescentes secuestradas a plena luz del día, en un espacio, la zona centro, plagado de policías municipales, federales y militares. Igualmente, la activista Marisela Ortiz, fundadora de Nuestras Hijas de Regreso a Casa, exiliada en 2011 de Ciudad Juárez tras ser amenazas de muerte por sus denuncias públicas, coincide a la hora de destacar un cambio cualitativo en perfiles y patrones en las víctimas, entre ellos, también un descenso significativo en las edades de estas. Ortiz, a quien entrevistamos durante el desarrollo de la presente investigación, destaca que "anteriormente, los victimarios solían escoger a mujeres cuyas edades oscilaban entre los 16 y los 20 años; este patrón cambia a partir del año 2008, donde las edades de las víctimas descienden progresivamente, siendo común encontrar jovencitas de 12 0 13 años desaparecidas o víctimas de feminicidio" (Entrevista personal a Marisela Ortiz, 2015).

Según los datos oficiales aportados por la Fiscalía de la Zona Norte, en 2013 seguían abiertos 117 casos de mujeres/niñas reportadas como desaparecidas. Durante el desarrollo de la labor documental, pudimos contactar, entrevistar y hacer seguimiento a un total de 24 familias de

\footnotetext{
${ }^{6}$ Esquivel, Jesús. (29 de marzo de 2012). Juárez, la ciudad más peligrosa del mundo: EU. Proceso. http:// www.proceso.com.mx/?p=302624
} 
mujeres desaparecidas entre enero de 2008 y enero de 2013. En este sentido, los datos obtenidos del estudio develan aspectos importantes a tener en cuenta que verifican las afirmaciones adelantadas, pudiendo afirmar que, en efecto, la mayor parte de las víctimas fueron vistas por última vez en la zona centro, a donde se desplazaron desde sus casas/centros de estudios bien a buscar trabajo, regresar a sus hogares o bien a estudiar (Gráfica 2).

\section{Gráfica 2}

VÍCTIMAS VISTAS POR ÚLTIMA VEZ EN EL CENTRO O SE DIRIGÍAN AL CENTRO

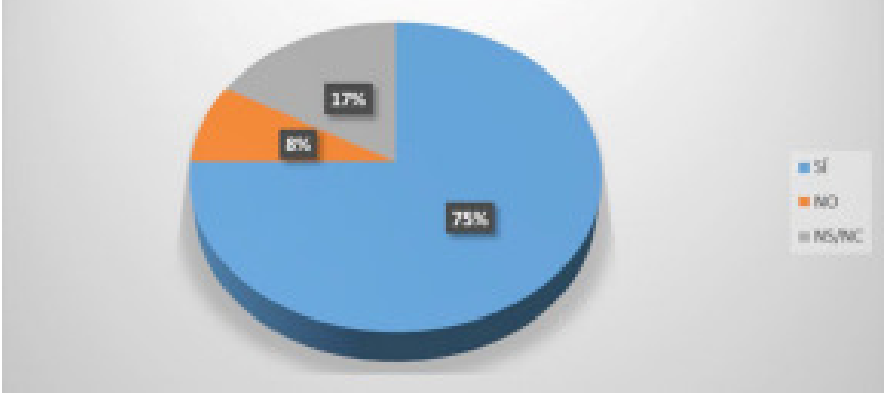

\#PraTodoMundoVer Gráfica circular, resultado del análisis sobre los lugares en los que fueron vistas por última vez o a dónde se dirigían las mujeres/niñas reportadas como desaparecidas entre 2008 y 2013 . El resultado indica "si" para un $75 \%$, en color azul; "no" para un $8 \%$, en naranja; y "no se sabe" para un $17 \%$, en gris. Elaboración propia a partir de las entrevistas llevadas a cabo en Ciudad Juárez.

A lo largo del desarrollo de la presente investigación detectamos el empleo de estrategias estructuradas por parte de las autoridades a la hora de afrontar los casos de desapariciones forzosas sistemáticas de adolescentes. Estas estrategias podemos analizarlas desde una triple perspectiva:

\section{Estrategia 1: Intentar disuadir a las madres de las jóvenes a la hora de presentar la denuncia por su desaparición}

Según datos oficiales aportados desde la Fiscalía General del Estado, entre 2008 y 2012 (cinco años) 117 mujeres/niñas fueron reportadas como desaparecidas en Ciudad Juárez sin ser localizadas. Como hemos podido constatar, numerosos testimonios de madres afectadas acreditan la existencia de una estrategia gubernamental de desprestigio de las víctimas para justificar su inacción. Un testimonio que atestigua estos hechos es el de Perla Reyes Loya, madre de Jocelyn Reyes, desaparecida en diciembre de 2012 en Ciudad Juárez cuando se dirigía al centro para acudir a una cita con una amiga. Tenía 13 años. Durante el transcurso de esta investigación participamos en numerosos eventos junto a Perla, a quien entrevistamos en diversas ocasiones y quien sigue sin noticia alguna del paradero de su hija. La pega de carteles con el rostro de Jocelyn por todo Juárez y su entorno, así como los rastreos por el Valle junto a otras madres buscando pruebas o evidencias que puedan llevar a la localización de su pequeña o de otras desaparecidas, se ha convertido ya en parte del día a día de Perla, quien, a lo largo de todos estos años, ha tenido que escuchar comentarios y argumentos insultantes de las autoridades:

Las autoridades no hacen su trabajo. Se limitan a decir que las niñas se van voluntariamente, que son problemáticas, que se van con los novios (...) habrá quienes se van con el novio, pero las que son secuestradas jamás son encontradas con vida (...) en mi caso hay datos que o bien no investigan o bien dejan que pase el tiempo para que se pierda esa pista (...) a veces pienso que si lo hacen es porque son los propios policías los que las secuestran. (Entrevista Personal a Perla Reyes. Octubre de 2015)

Centrándonos en la estrategia de disuasión a las familias afectadas para presentar la denuncia por la desaparición, destaca el hecho de que, de las 24 entrevistas realizadas a familias afectadas, 12 de ellas (50\%) admitieran que las Autoridades les pusieron "algún tipo de problema" a la hora de interponer el reporte de denuncia (Ver Gráfica 3). Llama la atención también que 18 de las 24 familias entrevistas (66\%) denunciaran abiertamente que, tras registrar la denuncia, las autoridades "les aconsejaran no dar difusión al caso y no contactar con periodistas o activistas".

La culpabilización, por parte de las autoridades, de las mujeres víctimas de feminicidio o desaparición forzosa ha sido una constante a lo largo de las últimas dos décadas. Ya desde los años 90 , gobernadores y altos mandos policiales han insistido en la estrategia de culpabilizar a las victimadas con el objetivo de minimizar sus graves negligencias. Entre 1993 y 2013 , el Estado de Chihuahua tuvo cuatro gobernadores: Francisco Barrio (PAN, 1992-1998) Patricio Martínez (PRI, 1998-2004), José Reyes (PRI, 2004 - 2010) y César Duarte (PRI, 2010-2016). La labor de las distintas administraciones estuvo marcada por una "relación de connivencia y/o permisividad" dominada 
por "la impunidad que ha permanecido y convertido en un elemento estructurante del sistema político en su conjunto" (RAVELO, 201 1, p.26). Una de estas estrategias, mantenida en la actualidad, ha sido la de difamar a las victimadas. La historiadora Patricia Galeana explica al respecto que:

En un principio estos crímenes fueron minimizados; primero se dijo que eran prostitutas (...) después se dijo que se lo buscaban por tener esta profesión. Cuando quedó demostrado que no era ese su trabajo, sino que eran mayoritariamente trabajadoras de las maquilas, se justificó su muerte porque tenían muchos novios, iban a bailar, usaban minifalda o salían solas por la noche (Patricia GALEANA, 2003, p. 4)

En este sentido, las entrevistas llevadas a cabo a 24 familias afectadas verifica el empleo de esta estrategia en una parte significativa de los casos; los datos obtenidos develan que:

\section{Gráfica 3}

FAMILIAS A LAS QUE PUSIERON PROBLEMAS A LA HORA DE DENUNCIAR

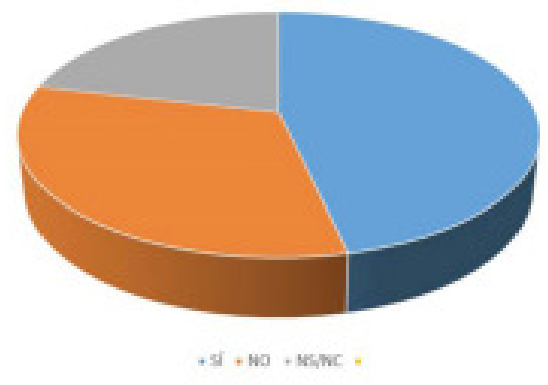

\#PraTodoMundoVer Gráfica circular, muestra el análisis de las respuestas dadas por las Autoridades a las familias afectadas a la hora de interponer las respectivas denuncias por las desapariciones de niñas/mujeres, con el "si" en azul a la derecha, "no" en color naranja en la parte inferior izquierda, y "no se sabe" en gris en la parte superior izquierda de la gráfica. Elaboración propia a partir de las entrevistas llevadas a cabo en Ciudad Juárez.

\section{Estrategia 2: Culpabilizar a las propias víctimas y acoso a las familias}

Paralelamente y como sucediera años anteriores, las autoridades vincularán a las víctimas, directa $o$ indirectamente, con bandas delincuenciales y estructuras del crimen organizado sin prueba alguna. Mediante esta estrategia se buscó culpabilizar a las victimadas de su destino, y, como consecuencia, dar por cerrados los expedientes sin tener acceso a una justicia real ni castigar o perseguir a los verdaderos culpables. En este sentido, la Fiscal, Patricia González, afirmará públicamente que:

Ahora la problemática de los feminicidios de mujeres está más bien relacionada con la delincuencia organizada, muchas mujeres han muerto en manos de la delincuencia organizada, de los grupos criminales, no es que ellas estén participando directamente en el narco, ellas son víctimas indirectas de la delincuencia organizada. (Misty IGLESIAS, 2010)

Analizando las palabras de la Fiscal, podemos observar cómo de forma velada se vincula a las mujeres víctimas de feminicidios con la delincuencia organizada, ya que, aunque matiza que no participaban "directamente" en estas redes criminales sí que, indirectamente, tenían vínculos con estas estructuras, identificando estos hechos dentro de los denominados narcofeminicidios, un nuevo espacio que fue empleado para catalogar de forma indiscriminada todos los feminicidios cometidos en Ciudad Juárez. La guerra por el control de Juárez silenciará los campos de reconocibilidad, siendo las mujeres y niñas violentadas y asesinadas durante este período cuerpos olvidados sistemáticamente por los actores que ostentaron el poder (Judith BUTLER, 2017).

Las fuerzas de seguridad han sido también acusadas de forma directa de hostigar y amenazar tanto a las familias afectadas como a periodistas que han dado seguimiento a este tipo de informaciones. En este sentido, durante la labor investigativa en Ciudad Juárez pudimos seguir en primera persona la campaña de acoso, intimidación y amenazas contra Carla Castañeda. Ella fue durante años una de las caras visibles más activas en la denuncia de las negligencias gubernamentales entorno a las investigaciones relativas a la búsqueda de niñas y mujeres desparecidas en Juárez entre 2008 y 2011 . Su hija, Cinthia Jocabeth Castañeda, despareció en el centro de Ciudad Juárez el 24 de octubre de 2008 cuando se disponía a comprar material para la escuela. Pese a que solo tenía 13 años, las autoridades se negaron a reportar su desaparición de forma inmediata alegando que tenían que pasar 72 horas ya que, según ellos, no era un caso de alto riesgo. A lo largo de todos estos años, hemos podido compartir numerosas conversaciones y entrevistas con Carla, cuyo activismo incesante para la búsqueda de su hija le llevó a ser amenazada en diversas ocasiones, aunque la intensidad de este hostigamiento se disparó en 2013 , justo tras realizar una "Caminata por la Vida", en la que algunas madres recorrieron a pie los más de $300 \mathrm{~km}$ que separan Juárez de Chihuahua para poder entrevistarse con el entonces Gobernador, César Duarte. Tal y como nos relató Carla años después, 
tras finalizar aquel acto, no carente de tensión, supuestos policías federales encapuchados se presentaron en su casa para, según su propio testimonio, "levantarla".

Fue una pesadilla (...) Después de aquella caminata que hicimos empezaron las amenazas, pero yo pensaba que sólo me querían asustar, pero no, iban en serio (...) aquel día yo recibo una llamada a las 6 de la mañana y me dicen que me vaya rápido de mi casa porque me iban a levantar, y así fue (...) salí rápido hacia la vivienda de una vecina, y desde allí pude ver cómo llegaron policías federales encapuchados (...) estuvieron buscándome, no se iban de mi casa (...) y fue entonces cuando sentí miedo; vi que iba en serio. (Entrevista personal, realizada a Carla Castañeda en octubre de 2017)

Desde el ámbito periodístico, el investigador Luis Chaparro, colaborador de publicaciones como Proceso o El Diario de Juárez, recuerda en este sentido que:

La militarización de Ciudad Juárez resaltó la ineficacia de las fuerzas de seguridad, pero no solo eso, también que los policías, federales y municipales, formaron parte del crimen organizado, y el ejército, a pesar de que hay menos evidencias concisas, ha tenido mucha participación por omisión y acción, descuidando la seguridad de la población que era su función (...) los feminicidios demostraron que las fuerzas de seguridad están involucradas directamente, que ellos trabajan para los grupos criminales que comenten los feminicidios, trasladando los cuerpos o a las jóvenes (...) los federales y municipales son parte de esas estructuras que atacan, violan y matan a las mujeres (...) en los feminicidios del Valle de Juárez se supo que los militares estuvieron implicados. (Entrevista personal a Luis Chaparro, diciembre 2017)

\section{Estrategia 3: Reducir las cifras reales y los casos de desapariciones forzadas a huidas voluntarias de las víctimas}

Ni los esfuerzos y avances logrados para la visibilización de las dimensiones de la problemática, ni la intervención y las sentencias condenatorias por parte de organismos internacionales han servido realmente para conseguir un cambio estructural en las instituciones gubernamentales a la hora de afrontar esta realidad. A pesar de que entre 2008 y 2013 más de 800 mujeres fueron asesinadas y más de un centenar de ellas fueron secuestradas de forma sistemática, el alcalde del municipio, lejos de asumir su responsabilidad y combatir esta realidad y las graves negligencias cometidas, señaló públicamente en 2015 que los feminicidios documentados en la ciudad eran una "leyenda negra", para generar "mala fama", añadiendo que "ese fenómeno provocó que se estigmatizara a Juárez con el asunto de los feminicidios" (David, MARTíNEZ, 2015).

Otra estrategia denunciada por activistas, periodistas y las propias familias para la minimización de las cifras reales y de la gravedad de los hechos ha sido la ocultación de cuerpos de mujeres asesinadas con el objetivo de minimizar las cifras y reducir la problemática a desapariciones voluntarias de adolescentes. Ernestina Enríquez, madre de Adriana Sarmiento Enríquez (joven de 15 años desaparecida en la zona centro en enero 2008) ha vivido en primera persona la desidia gubernamental a la hora de abordar las desapariciones de adolescentes que, como su hija, fueron secuestradas por el simple hecho de ser jóvenes, mujeres y humildes. Ernestina tuvo que soportar durante tres años toda una cadena de mentiras gubernamentales que incluyeron investigaciones y pistas ficticias sobre la búsqueda de su hija, ya que en noviembre de 2011 se sabría que durante más de tres años las autoridades tuvieron oculto el cuerpo de Adriana en el Servicio Médico Forense (SEMEFO), minimizando de este modo el número real de feminicidios. Ernestina denuncia en este sentido que:

Ser mujer, bonita y pobre es una desgracia en Ciudad Juárez (...) Las autoridades tenían los restos de mi hija en el SEMEFO y no me lo entregaron hasta que ellos quisieron (...) los asesinos se las llevan como quieren, las hacen lo que quieren y las tiran como basura (...) seguimos esperando justicia, pero justicia real, no falsos culpables (...) las muertas de Juárez no son una leyenda negra, son una realidad. (Entrevista personal a Ernestina Enríquez, octubre de 2015)

Una lectura cuantitativa de este capítulo a través de las entrevistas realizadas en Ciudad Juárez avala esta denuncia. En este punto, de las 24 familias entrevistadas, un total de 22 creen que las Autoridades han ocultado cuerpos de mujeres asesinadas en la morgue para minimizar los datos reales. Aunque resulta complejo cifrar de forma exacta tanto el número de mujeres desaparecidas como el de asesinadas ante la disparidad existente entre los datos oficiales y los aportados por organizaciones y las propias familias, podemos afirmar que de las más de 100 mujeres/niñas desaparecidas durante el proceso de militarización de la ciudad y su entorno, al menos 22 de estas jóvenes han sido localizadas años después de su desaparición en el entorno del Arroyo del Navajo, en el Valle de Juárez. Cuando las jóvenes fueron trasladadas a esos espacios, la zona estaba controlada por retenes militares, es decir, sus victimarios trasladaron sistemáticamente los cuerpos de las jóvenes con la complicidad de miembros de las fuerzas de seguridad. Un dato revelador que pone en duda la versión oficialista es el hecho que algunas de las víctimas 
presentaban aún las mismas ropas con las que las que fueron vistas por última vez años antes. ${ }^{7}$ Todos estos datos evidencian que, al menos entre 2008 y 2013 , han existido una o varias estructuras feminicidas que han actuado de forma sistemática en la ciudad y su entorno para secuestrar a jóvenes con edades comprendidas mayoritariamente entre los 13 y los 18 años con un marcado perfil físico/social. No podemos confirmar si esta/s estructura/s sigue/n aún hoy activa/s, pero sí que durante años secuestraron, agredieron, retuvieron y, finalmente, asesinaron a decenas de mujeres, dejando sus cuerpos en zonas desérticas muy alejadas del centro de Ciudad Juárez. Estas y otras evidencias denunciadas han demostrado no sólo el papel negligente de la policía federal desplegada en Juárez y de los soldados controladores del Valle de Juárez en estos capítulos, sino también su posible implicación activa, como denunció un testigo protegido, quien admitió "la complicidad de policías municipales, estatales, federales e incluso del Ejército Mexicano que patrullaba entonces en la Operación Conjunta Chihuahua" (Sandra RODRÍGUEZ, 2015).

\section{Conclusiones}

El feminicidio documentado en Ciudad Juárez entre 2008 y 2013 se inscribe en el marco de una violencia de género estructural, siendo una de sus expresiones más extremas en tanto tramita el odio hacia las mujeres, vulnerando sus derechos fundamentales hasta el punto de llegar a la comisión del asesinato o su tentativa. Sin embargo, es muy importante destacar que para que el feminicidio logre consumarse requiere del concurso de unas autoridades negligentes y en ocasiones coludidas con los agresores, haciendo de la impunidad la constante impronta del crimen.

Retomando las hipótesis planteadas en el inicio de nuestra investigación, podemos concluir que, en efecto, la llegada masiva de miles de miembros de las Fuerzas de Seguridad a Ciudad Juárez en el marco del Operativo Conjunto Chihuahua no supuso una mejora para la seguridad de la población en general y de las mujeres en particular (Amnistía Internacional, 2009). Al contrario, su inclusión vino acompañada por un aumento de los crímenes y delitos por razones de género. Centrándonos en el período en el que se desarrolló nuestra investigación, 2008- 2013, la violencia feminicida no sólo no descendió respecto a los años precedentes, sino que aumentó, disparándose los casos de feminicidios y desapariciones de mujeres y niñas, y registrándose un preocupante y notable agravamiento respecto a los feminicidios sexuales y secuestros sistemáticos de adolescentes. La llegada de miles de policías federales y el proceso de militarización sufrido en la ciudad no supuso una mejora de los niveles de seguridad, todo lo contrario, los índices de violencia se agudizaron, especialmente los referidos a la misoginia. El Estado ha sido y es parte del problema debido a su nula sensibilidad e inexistente compromiso para afrontar los hechos de manera eficiente e investigar con nitidez los hechos y las autorías de estos crímenes. Ampararse en el clima de violencia generalizado de la ciudad no fue más que estrategia para minimizar un feminicidio sistemático.

Las autoridades, a lo largo de todos estos años, han sido cuanto menos negligentes, han buscado difuminar de forma estratégica estos casos de violencia misógina en el contexto de la violencia generada por la denominada como Guerra contra el narco. Esta estrategia, como hemos analizado, ha recurrido a la simplificación de los hechos con el objetivo de minimizar el fenómeno y diluirlo, vinculando, además, a las víctimas con estructuras delictivas y actos criminales sin ningún tipo de prueba consistente. La realidad es que, como señala la antropóloga Marcela Lagarde (2008), nos situamos ante una violencia de género sistematizada en Ciudad Juárez no es algo coyuntural, sino que, como argumenta la investigadora Julia Monárrez, es resultado de un contexto estructural fundamentado en un sistema patriarcal que ha propiciado la impunidad mediante la minimización de estos crímenes con una cadena de argumentos e instrumentos repetidos a lo largo de los años y las diferentes administraciones. Una de las herramientas empleadas para mantener y solidificar este sistema asimétrico de poder ha sido la comunicación y, como tal, los actores sociales y políticos han moldeado los instrumentos necesarios para el control de los mensajes, imponiendo roles y estereotipos para conceptualizar los modelos de "mujer o varón en la medida en que se funciona como tal en la estructura heterosexual dominante" (María Celeste BIANCIOTTI, 2015, p. 516). Como señala la periodista Rosa Isela PÉREZ (2012, p. 1 14), exiliada por sus denuncias e investigaciones periodísticas alrededor de la red de mentiras existentes tras los feminicidios sexuales de Juárez, ha existido y existe un "contubernio" entre "algunos medios de comunicación" y "las autoridades" para poner en marcha para "desprestigiar a los familiares de las víctimas, las organizaciones civiles y los periodistas" acusándoles de crear un "mito".

Como hemos analizado, los argumentos aportados por numerosos cargos públicos y políticos a lo largo de las últimas décadas, reduciendo los asesinatos de más 1.500 niñas, y la comisión de al menos 250 feminicidios sexuales sistemáticos a un "estigma" o "leyenda negra" que soporta la ciudad, producto de las acciones de investigadoras, activistas, periodistas y familias en busca de lucro es parte de esta estrategia, la cual, aunque con matices, sigue repitiendo su modus operandi,

7 Dato confirmado a los/as autores/as de la investigación por las familias de al menos seis de las jóvenes localizadas en El Navajo entre 2008 y 2013. 
incluyendo el desprestigio y el acoso a los familiares de las jóvenes secuestradas y/o asesinadas que son "maltratados institucionalmente, violentados y se les impide el acceso a la justicia" (LAGARDE 2012, p.264).

\section{Referencias}

AMNISTÍA INTERNACIONAL. Nuevos informes de violaciones de derechos humanos a manos del ejército. México, 2009.

BERLANGA, Mariana. "El espectáculo de la violencia en el México actual: del Feminicidio al juvenicidio". Athenea Digital, Barcelona, v. 15, n. 4, p. 105-128, 2015.

BIANCIOTTI, María Celeste. "Haciendo sexo / género / deseo en la(s) noche(s) cordobesa(s): una etnografía sobre intercambios (hetero) eróticos”. Etnográfica [En línea]. Portugal, 2015, v. 19, n. 3. Disponible en http://etnografica.revues.org/4099. DOI: 10.4000/etnografica.4099. Acceso el 10/1 1/ 2017.

BROOKS, David. "Se quintuplicaron los abusos de militares en México, alertan en EU". La Jornada. [En línea]. México, 26 de abril de 2013. p. 19. Disponible en http://www.jornada.unam.mx/2013/04/ 26/politica/019n1pol. Acceso el 01/11/2015.

BULLEN, Margaret; DíEZ, Carmen, (Orgs.). Retos Teóricos y nuevas prácticas. Bilbao (España): Universidad del País Vasco, 2008.

BUTLER, Judith. Marcos de guerra, Las vidas Iloradas. Bogotá (Colombia): Planeta, 2017.

CEDEHM. 2012. Juárez y Chihuahua: Guerra contra el narcotráfico y recomendaciones de la CEDAW. México, 2012.

FACCIO, Alda. "Feminismo, género y patriarcado". In: FACCIO, Alda; FRIES, Lorena (Comp.). Género y Derecho. Santiago de Chile: La morada: corporación de desarrollo de la mujer, 1999.

GALEANA, Patricia. "Historia de un feminicidio: Las muertas de Juárez". In: ÁLVAREZ DE LARA, Rosa María. La memoria de las olvidadas, las mujeres asesinadas en Ciudad Juárez. México: Universidad Nacional Autónoma de México, 2003.

GONZÁLEZ, Sergio. Huesos en el desierto. Barcelona: Anagrama, 2002.

JUÁREZ, Javier. Estrategias y campañas de desinformación gubernamental y manipulación informativa en relación a los feminicidios y secuestros de mujeres y niñas en Ciudad Juárez entre 1993 y 2013. 2015. Tesis (Doctorado en Periodismo) - Facultad de Ciencias de la Información, Universidad Complutense de Madrid, Madrid, España.

IGLESIAS, Misty. "Suben los narcofeminicidios en Chihuahua". 2010. Disponible en http:// www.xepl.com.mx/completa $1 . p h p ? s=$ region\&i=48166. Acceso el 15/04/2017.

INEGI - INSTITUTO NACIONAL DE ESTADÍSTICA. "División Municipal”. (2015). Web Cuentame. Disponible en http://cuentame.inegi.org.mx/monografias/informacion/chih/territorio/div_municipal.aspx?tema $=$ me\&e $=08$. Acceso el 15/1 1/2015.

LAGARDE, Marcela. "Antropología, feminismo y política: violencia feminicida y derechos humanos de las mujeres". In: BULLEN, Margaret; DÍAZ, Carmen. Retos Teóricos y nuevas prácticas. País Vasco España: Editorial Ankulegi, 2008.

LAGARDE, Marcela. "Las leyes de violencia de género en México: medidas de prevención y sensibilización". In: REDUR (Revista Electrónica del Departamento de Derechos de la Universidad de La Rioja), 10 de diciembre de 2012. p. 253-275.

LIMAS, Alfredo. "Seguridad humana, violencia feminicida, democracia y capital". Regions and Cohesion, New York, v. 4, p. 74-88, 2014.

MARTíNEZ, David. "Feminicidios en Juárez son "leyenda negra" para generar "mala fama", afirma el Alcalde". 2015. Disponible en http://www.sinembargo.mx/20-02-2015/1257695. Acceso el 31/ $01 / 2017$.

MONÁRREZ, Julia Estela. "Elementos de Análisis del feminicidio sexual sistemático en Ciudad Juárez para su viabilidad Jurídica". In: SEMINARIO INTERNACIONAL FEMINICIDIO, DERECHO Y JUSTICIA, México DF, 8-9 diciembre 2004. 
MONÁRREZ, Julia Estela. "Peritaje sobre Feminicidio Sexual Sistemático en Ciudad Juárez Presentado ante la Corte Interamericana de Derechos Humanos". Santiago de Chile. 2009 Disponible en http:/ /www.corteidh.or.cr/docs/casos/expedientes/Mon\%C3\%A1 rrez.pdf. Acceso el 31/01/2017.

MONÁRREZ, Julia Estela. "Las diversas representaciones del feminicidio y los asesinatos de mujeres en Ciudad Juárez, 1993- 2005". In: CERVERA, Luis; FUENTES, César; MONÁRREZ, Julia; RUBIO, Rodolfo (Coords.). Violencia contra las mujeres e inseguridad ciudadana en Ciudad Juárez. México: Miguel Ángel Porrúa Editores, 2010.

PÉREZ, Rosa Isela "Mujeres asesinadas en Ciudad Juárez: La justicia apenas comienza". In: BERNABÉU, Salvador; MENA, Carmen (Coords.). El feminicidio de Ciudad Juárez. Repercusiones legales y culturales de la impunidad. Sevilla: Universidad Internacional de Andalucía. 2012.

RAVELO, Patricia. El fenómeno del feminicidio: Una propuesta de recategorización. México: Centro de Investigaciones y Estudios Superiores en Antropología Social (CIESAS), 2008.

RAVELO, Patricia. Violencia sexual y de género en Ciudad Juárez, Chihuahua. Estructura, política, cultura y subjetividad. México: Ediciones Eón, 2011.

RODRÍGUEZ, Sandra. "Juicio Oral por feminicidio en Juárez implica a militares; las usaban para placer: testigo". Sin Embargo. [En línea]. México, 28 de junio de 2015. Disponible en http:// www.sinembargo.mx/28-06-2015/1395929. Acceso el 23/1 1/2015

SEGATO, Rita. La escritura en el cuerpo de las mujeres asesinadas en Ciudad Juárez. Territorio, soberanía y crímenes de segundo estado. Buenos Aires: Tinta Limón, 2013.

WASHINGTON, Diana. Cosecha de Mujeres: Safari en el desierto mexicano. Barcelona (España): Océano, 2005.

WEB CUENTAME. Disponible en http://cuentame.inegi.org.mx/monografias/informacion/chih/territorio/ div_municipal.aspx?tema $=$ me\&e $=08$. Acceso el 15/1 1/2015.

Javier Juárez Rodríguez (jjuarez@udem.edu.co) es Doctor en Periodismo por la Universidad Complutense de Madrid y Docente- Investigador Grupo GRECO de la Facultad de Comunicación de la Universidad de Medellín, Colombia. Especialista en Comunicación, Género y Derechos Humanos.

Nora Elena Botero Escobar (nebotero@udem.edu.co) es Magister en Comunicación Educativa de la Universidad Tecnológica de Pereira y la Universidad de Medellín, Máster en Mediación Social con Enfoque de Género de la Universitat Jaume I, Castellón de la Plana, España y Docente- Investigadora Grupo GRECO de la Facultad de Comunicación de la Universidad de Medellín, Colombia.

Natalia Grisales Ramírez (nrgrisales@udem.edu.co) es Magister de en antropología Universidad Nacional Autónoma de México y Docente-Investigadora Grupo HOLOGRÁFICO de la Facultad de Comunicación de la Universidad de Medellín, Colombia.

\section{COMO CITAR ESTE ARTÍCULO, DE ACUERDO CON LAS NORMAS DE LA REVISTA:}

JUÁREZ, Javier; BOTERO, Nora; GRISALES, Natalia. "Estrategias del Estado mexicano para minimizar los feminicidios". Revista Estudos Feministas, Florianópolis, v. 28, n. 1, e5781 1, 2020.

\section{CONTRIBUCIÓN DE AUTORÍA}

Javier Juárez Rodríguez: Investigador principal

Nora Elena Botero: Co-Investigadora

Natalia Grisales: Co-Investigadora

FINANCIACIÓN

Universidad de Medellín, Colombia

CONSENTIMIENTO DE USO DE IMAGEM

No aplicable 


\section{APROBACIÓN DE COMITÉ DE ÉTICA EN INVESTIGACIÓN}

No aplicable

\section{CONFLICTO DE INTERESES}

No existe conflito de intereses

\section{LICENCIA DE USO}

Este artículo está licenciado bajo la Licencia Creative Commons CC-BY Internacional. Con esta licencia se puede compartir, adaptar, crear material para cualquier objetivo, siempre que se le atribuya la autoría.

\section{HISTORIAL}

Recibido el 20/06/2018

Presentado nuevamente el 10/04/2019

Presentado nuevamente el 31/05/2019

Aprobado el 31/05/2019 